\title{
REGADENOSON IN EUROPE: FIRST- YEAR EXPERIENCE OF REGADENOSON STRESS COMBINED WITH SUBMAXIMAL EXERCISE IN PATIENTS UNDERGOING MPS
}

M B Brinkert, ${ }^{1}$ E R Reyes, ${ }^{1}$ S W Walker, ${ }^{1} \mathrm{~K}$ L Latus, ${ }^{1}$ A M Maenhout, ${ }^{1}$ K S Standbridge, ${ }^{1}$ R M Mizumoto, ${ }^{1}$ S N Nkomo, ${ }^{1}$ K W Wechalekar, ${ }^{1}$ $\mathrm{R}$ U Underwood ${ }^{2}{ }^{1}$ Royal Brompton Hospital/Department of Nuclear Medicine; ${ }^{2}$ Royal Brompton Hospital/Department of Nuclear Medicine/National Heart \& Lung Institute Imperial College

\section{doi:10.1136/heartjnl-2013-304019.96}

Background Regadenoson is a selective A2a specific adenosine receptor agonists. It has been developed to avoid side effects associated with common pharmacological stress agents. European approval was granted by the EMA in 2010. The aim of this study was to assess the side effect profile of regadenoson and to compare this experience with other forms of stress used over the same period.

Methods Since July 2011 we prospectively studied 1764 consecutive patients referred for MPS. All clinical, stress and imaging data have been recorded and analysed using the Excel Data Analysis Toolpak and SPSS. Symptoms during stress were recorded and defined as mild, moderate or severe. An adverse event was defined as any symptom that persisted for more than $30 \mathrm{~min}$ or that required investigation or treatment. Adenosin, dobutamine and dynamic exercise were administered and done according to Royal Brompton Patient Group Direction (PGD). Regadenoson was given as a $400 \mu \mathrm{g}$ bolus intravenously over 10-30 s followed by a saline flush over $10 \mathrm{~s}$ and then the radiopharmaceutical.

Results 130 patients underwent adenosine stress, 1581 regadenoson stress, 39 dobutamine stress and 14 dynamic exercise stress. Symptoms were common with all forms of pharmacological stress occurring in $75 \%$ with adenosine, $63 \%$ with regadenoson and $46 \%$ with dobutamine. Chest discomfort and flushing occurred more commonly with adenosine (29\% and $25 \%$ respectively) than with regadenoson $(12 \%$ and $7 \%$ ), but light headedness more common with regadenoson $(7 \%)$ than with adenosine (1\%). Twelve patients with regadenoson $(1 \%)$ had diarrhoea compared with none with adenosine. The severity of symptoms did not differ between agents being mild, moderate and severe $84.1 \%, 14 \%$ and $1.9 \%$ with adenosine, $88.1 \%, 10.1 \%, 1.7 \%$ respectively with regadenoson and $82.4 \%$, $17.7 \%, 0 \%$ with dobutamine. Eight patients had adverse events, all with regadenoson, although the difference was not statistically significant $(p=0.818)$. Three events were moderate and two severe, the latter with sinus arrest and asystole lasting $30 \mathrm{~s}$ and $10 \mathrm{~s}$ and requiring CPR. All patients recovered fully without sequelae or admission to hospital. No patient developed bronchospasm with regadenoson

with the exception of a single patient without known airways disease who developed mild bronchospasm that responded to salbutamol inhaler.

Conclusions We have studied 1764 stress tests for MPS over a 12-month period in order to assess the symptom profile of regadenoson in the largest European cohort to date. Regadenoson combined with exercise is well tolerated, notably also in patients with asthma/ COPD. The majority of adverse events were vaso-vagal episodes without sequelae. There is no clear direct mechanism by which regadenoson might cause vaso-vagal syncope. 